\title{
Sleep bruxism: challenges and restorative solutions
}

\section{Cristiane Machado \\ Mengatto \\ Fábio Herrmann Coelho- de-Souza \\ Oswaldo Baptista de Souza Junior}

Department of Conservative Dentistry, School of Dentistry, Federal University of Rio Grande do Sul (UFRGS), Porto Alegre, Brazil

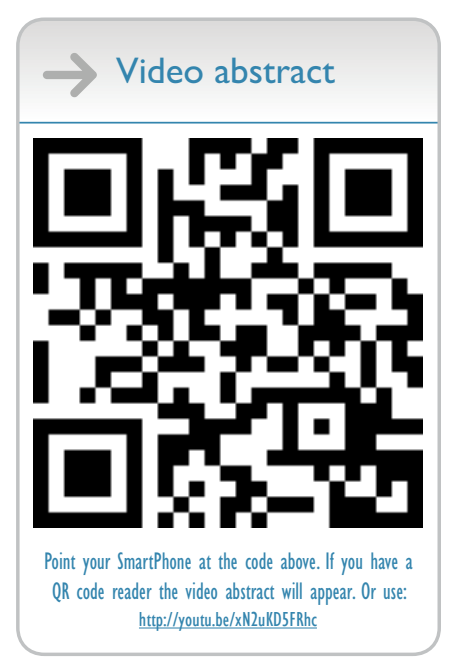

Correspondence: Cristiane Machado Mengatto

Department of Conservative Dentistry, School of Dentistry, Federal University of Rio Grande do Sul - Rua Ramiro Barcelos, 2492, Porto Alegre, Rio Grande do Sul, 90035-003, Brazil,

Tel +55 5l 999l 4176

Email cristianemach@yahoo.com.br
This article was published in the following Dove Press journal:

Clinical, Cosmetic and Investigational Dentistry

22 April 2016

Number of times this article has been viewed

Abstract: Bruxism is a parafunctional activity related to clenching or grinding the teeth and tooth wear can be a consequence of sleep bruxism (SB). Management of severe tooth wear due to SB is a challenging situation because of the common reduced amount of remaining dental structure and loss of vertical dimension of occlusion. Rationale for the planning of oral rehabilitation of patients with SB presenting severe tooth wear should rely on evidence-based approaches; however, few studies have discussed properties of dental materials for SB rehabilitation and how to cosmetically manage severe tooth wear. This review aimed to provide an overview into bruxism cosmetic rehabilitation and how this can be implemented with good outcomes for the patient.

Keywords: sleep bruxism, restoration, rehabilitation, prosthodontics, dentistry

\section{Introduction}

Bruxism can be defined as a diurnal or nocturnal parafunctional activity including repetitive jaw-muscle activity characterized by clenching or grinding of the teeth and/or by bracing or thrusting of the mandible. ${ }^{1,2}$ It can occur during wakefulness (indicated as awake bruxism) or sleeping (indicated as sleep bruxism [SB]), forming two distinct entities. New concepts have pointed that SB is a sleep-related movement disorder $^{2}$ and SB episodes occur during transient arousal, showing a sequence of systemic excitatory events including an increase in sympathetic activity before SB onset ( -8 to -4 minutes); followed by increased electroencephalographic activity ( -4 seconds); tachycardia which occurs 1 second before SB; and increased respiratory amplitude concomitant with the occurrence of rhythmic masticatory muscle activity (RMMA), which characterizes the SB. ${ }^{3,4}$ Individuals with SB have $67 \%$ more microarousals per hour of sleep (five arousals per hour) than normal individuals. ${ }^{5}$ Normal individuals have approximately 1 RMMA per hour of sleep, ${ }^{6,7}$ while individuals with SB may have up to 12 RMMA per hour of sleep. ${ }^{5,7,8}$

One of the signs that this parafunction is present in an individual is the sound of grinding teeth, noticed either by a partner or by the patients themselves. Although the clinical diagnosis of SB based on patients' self-reporting and clinical examination according to American Academy of Sleep Medicine minimal criteria ${ }^{9}$ is generally accepted for research and clinical use, the actual activity of SB can only be assessed and confirmed by polysomnography (electromyogram, audio/video). ${ }^{8}$ According to an international group of bruxism experts, "possible" SB is diagnosed based on self-report by means of questionnaires and/or the anamnestic part of a clinical 
examination. "Probable" SB is based on self-report plus the inspection part of a clinical examination. "Definite" SB is based on self-report, clinical examination, and polysomnographic recording, preferably along with audio/video recordings. ${ }^{2}$ A number of hypotheses have been raised to explain the complex mechanism involved in the genesis of SB, but the etiology of this parafunction and the factors related to its pathophysiology are yet to be fully elucidated.,10-12

Discussions about SB etiology and treatment gained widespread attention in the last decade and have changed some paradigms about SB held by clinicians. SB etiology is a complex physiological process which involves different functional pathways related to sleep, response to stress, brain activity, muscle activity, cardiac function, and breathing. . $^{1,4,10,12-17}$ Several phenomena can disturb sleep structure and lead to SB occurrence, such as chronic headache episodes, epileptic encephalopathy, and migraine, particularly in children and adolescents. ${ }^{18-21}$ In adults, recent findings reported in the literature suggest that there is a relationship between intraesophageal acidity, gastroesophageal reflux disease (GERD), and SB occurrence. ${ }^{13-15,17}$ The exclusive observation of surface loss of dental hard tissues no more confirms a definite clinical diagnosis of SB as initially thought. ${ }^{22}$ In many situations, the tooth wear found in patients with bruxism can be associated with attrition and erosion and increases when related to gastric reflow and acid feeding, causing severe tooth wear. ${ }^{23}$ However, no clinical study that investigated the influence of SB on tooth wear has been reported. Anyway, tooth wear remains the most common clinical consequence of SB. Excessive occlusal forces occurring in SB as well as tooth grinding also favor a number of dental problems such as abrasion and chipping of teeth and/ or prosthetic restorations, orofacial pain, and teeth sensitivity, pulpal pathology, tooth wear or fractures of teeth and restorations, or even damage of implants. ${ }^{24}$ In advanced SB cases, damage to teeth may result in premature loss of dentition. The lack of a definitive treatment for SB condition has led to palliative approaches to manage SB and its negative consequences to the dentition. Furthermore, the dental complications found in SB patients pose a number of clinical challenges to restore functional and esthetic oral conditions of these patients.

This review aims to provide an overview into bruxism cosmetic rehabilitation and considerations about the choice of restoring materials and techniques.

\section{The management of SB oral complications}

Many patients are not aware that they grind their teeth during sleep. In this context, the dentist has an important role in the early diagnosis and management of $\mathrm{SB}$, in order to prevent severe damages to the dental structure. When SB is diagnosed early, tooth wear stays limited to the enamel of anterior teeth only and the decision whether to restore worn facets is dependent on the patient's esthetic demands and financial availability. Severe tooth wear is difficult to be clinically managed because of the reduced amount of remaining dental structure. Patients presenting severe tooth wear frequently exhibit loss of occlusal vertical dimension and severe esthetic problems which may require multidisciplinary approaches for rehabilitation, such as periodontal surgery, endodontic treatment, intraradicular post and cores, direct and indirect restorations. Although bruxism is not a life-threatening condition, excessive shortening of anterior teeth by tooth wear can negatively impact patient's quality of life and be associated with functional limitations, physical pain, and social disability. ${ }^{25}$ This impact is comparable with that of edentulousness. ${ }^{26}$ Thus, esthetic and functional reconstruction of severely worn teeth is essential for reestablishing individual's self-esteem and social interactions. It must be considered that extensive rehabilitation treatments have some limitations related to patients' financial restrictions, which may limit the treatment decision making. Moreover, there is little scientific evidence available on the rehabilitation of SB oral complications which poses additional challenges to restoration of SB tooth damages. ${ }^{27}$ Severe bruxism is often associated with mechanical and technical complications in cosmetic dentistry and prosthetic rehabilitations. Extensive oral treatment of SB is complex, especially when there are reduced remaining dental structure and interocclusal space reduction due to loss of vertical dimension.

The management of severely worn dentition is challenging and can be disappointing for the patient as for the clinician, if detailed and interdisciplinary dental planning is not considered. ${ }^{28}$ Good ways to begin treatment planning for SB oral rehabilitation is having a careful oral diagnosis and taking an in-depth look at patient's occlusion and the stone models mounted in an articulator in the patient's habitual maximum intercuspation. The severity of extensively worn dentitions can be classified into three different categories, which can guide the restorative treatment planning process as part of tooth restoration and esthetics enhancement. ${ }^{29}$ Patients showing excessive tooth wear and loss of the occlusal vertical dimension are classified in category $\mathrm{I}^{29}$ (Figure 1). For these patients, reestablishment of posterior tooth support and an increase in vertical dimension, which is further discussed below, may be necessary for adequate tooth restoration. Patients with severe tooth wear but without 


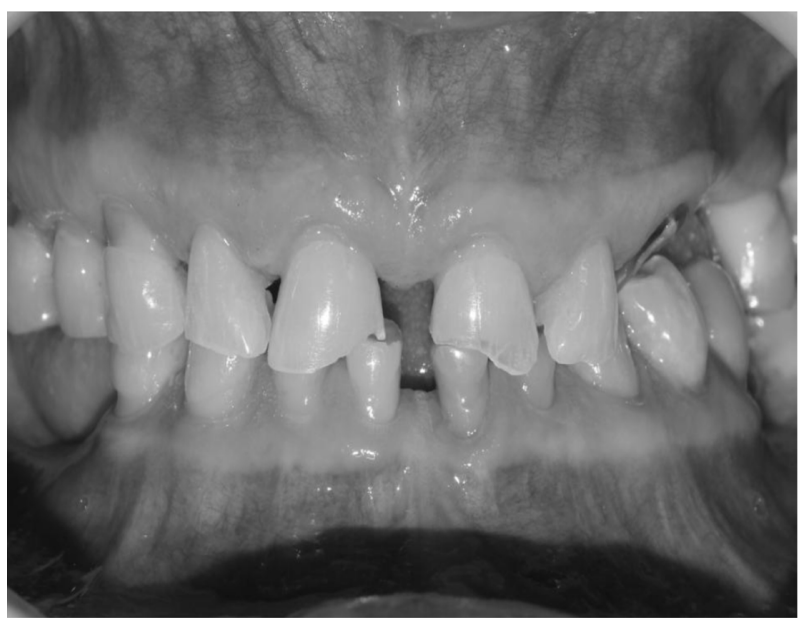

Figure I Patient with severe tooth wear and loss of vertical dimension particularly related to sleep bruxism and loss of posterior teeth.

loss of the occlusal vertical dimension have space available for the placement of restorations and are included in category II (Figure 2). Patients in this group typically have adequate posterior support and a long history of bruxism. In these patients, the continuous eruption of the teeth helped maintaining the occlusal vertical dimension. ${ }^{29}$ Patients in category III (Figure 3) have severe tooth wear and no loss of occlusal vertical dimension, but differ from category II in having limited space available. ${ }^{29} \mathrm{~A}$ more difficult condition is when there is an occlusal plane discrepancy, because an uneven amount of restoration is required. ${ }^{30}$

Increasing vertical dimension and providing sufficient space for restoration is challenging but necessary. This increase in vertical dimension can be done through provisional overlay removable partial dentures (Figure 4). Overlay removable partial dentures are provisional acrylic resin

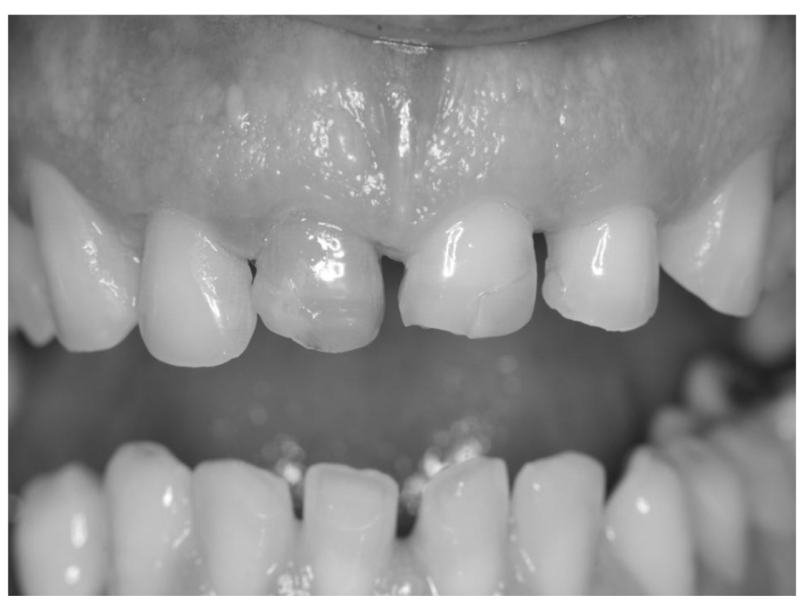

Figure 2 Severe tooth wear without loss of vertical dimension. The anterior teeth are affected more than the posterior teeth.

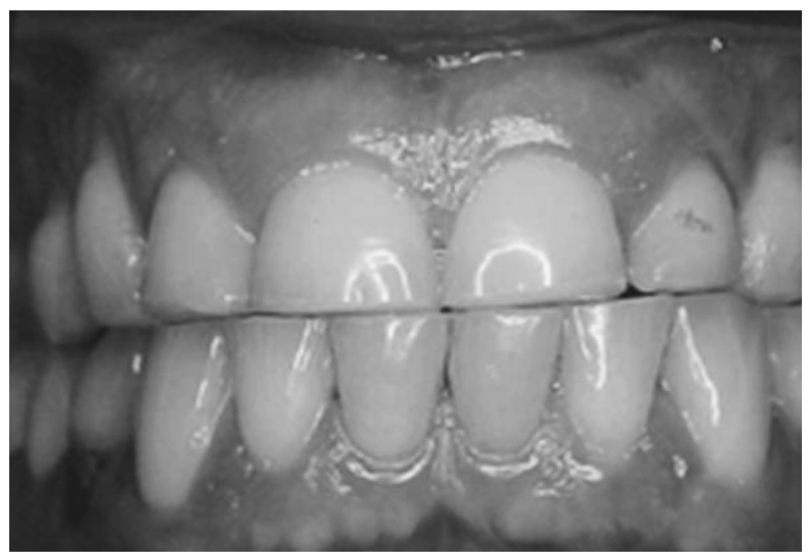

Figure 3 Patient with severe tooth wear of anterior teeth without loss of vertical dimension and limited space available for restoration.

dentures with partial acrylic teeth at the anterior region and acrylic resin or metal occlusal surfaces at the posterior region. It allows covering of the worn tooth and roots, especially to increase vertical dimension in patients with severely worn dentition. The use of provisional overlays is a simple, effective, and affordable option to help the professional increase patients' vertical dimension and reestablish esthetic and function during restoration with direct composite resins and indirect ceramic crowns (Figures 5-8). ${ }^{31}$

The Dahl's concept has long been used to increase the occlusion vertical dimension and create interocclusal space in order to restore patients with severe tooth wear, especially found in patients with bruxism. Dahl's concept postulates the use of a "partial bite raising appliance" to have the intrusion of the anterior teeth in contact with the appliance and the eruption of the separated posterior teeth. ${ }^{32,33}$ Alfadda ${ }^{24}$ proposed the increasing of the occlusal vertical dimension by $2-3 \mathrm{~mm}$ through an overlay partial denture for cases with severe tooth wear rehabilitation, to allow proper tooth reconstruction with

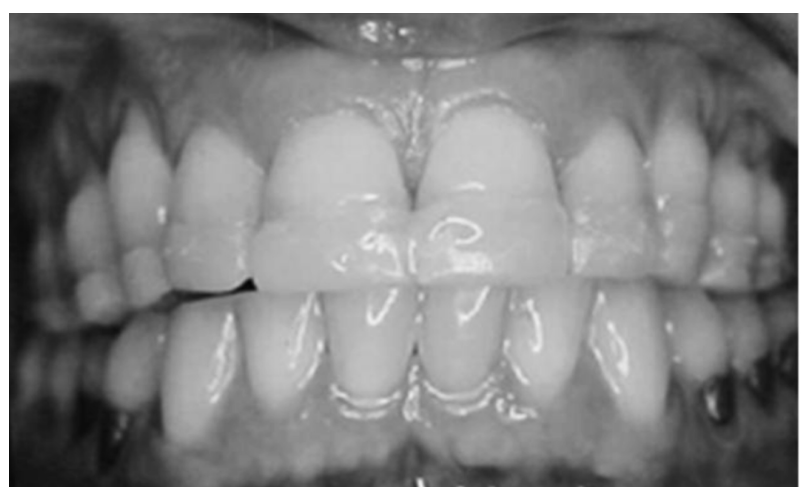

Figure 4 Provisional overlay denture was confectioned with acrylic resin over the existent worn teeth to provide increase in the vertical dimension for adequate cosmetic restoration. 


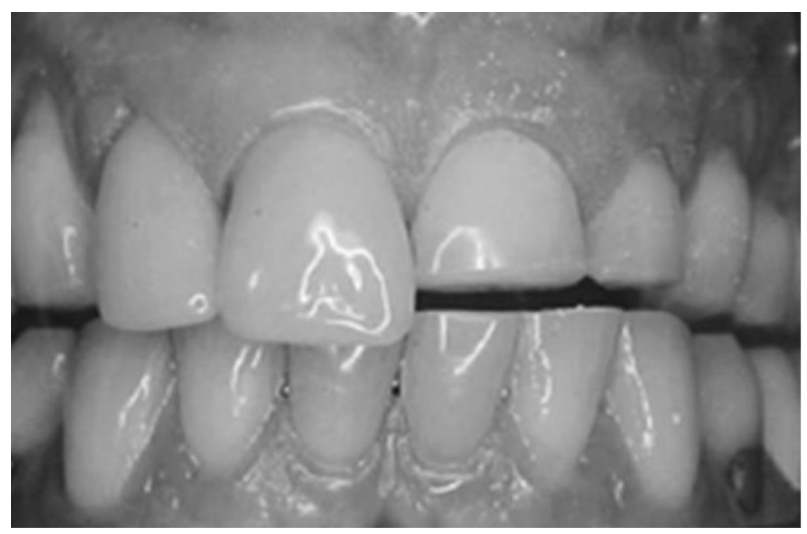

Figure 5 Right anterior teeth were prepared for ceramic fixed prosthesis and received provisional acrylic crowns, these teeth of the overlay were cut with a metallic bur and removed from the overlay. Left teeth have not been prepared yet. The patient kept using the acrylic overlay during the restorative process with provisional crowns and/or direct composite restorations.

direct or indirect restorations (Figure 5). Hamburger et $\mathrm{al}^{34}$ also worked with the increasing of the occlusal vertical dimension to rehabilitate patients with severe tooth wear, but with direct composite resins. Nevertheless, Machado et $\mathrm{al}^{23}$ highlighted the importance of using an interocclusal splint device before and after the restorative treatment with composite for bruxism patients, either for muscular and joint repositioning or to protect the restored structures. ${ }^{23}$

\section{Direct and indirect restorations}

After functional and esthetic analysis, composite resins direct restorations and metal-ceramic and ceramic crowns are options to repair tooth wear caused by bruxism. ${ }^{33}$ The choice to select a material for restoration of worn teeth is influenced by multiple factors. The development of adhesive techniques has provided conservative approaches to restore severely worn teeth through the use of direct resin composite and a silicone

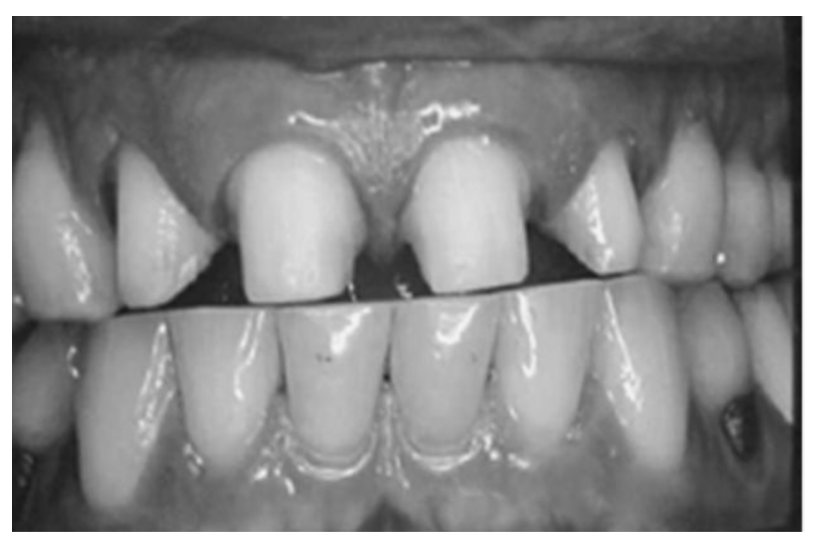

Figure 6 All anterior teeth were prepared for ceramic fixed prosthesis, while posterior teeth remained with the overlay to increase vertical dimension.

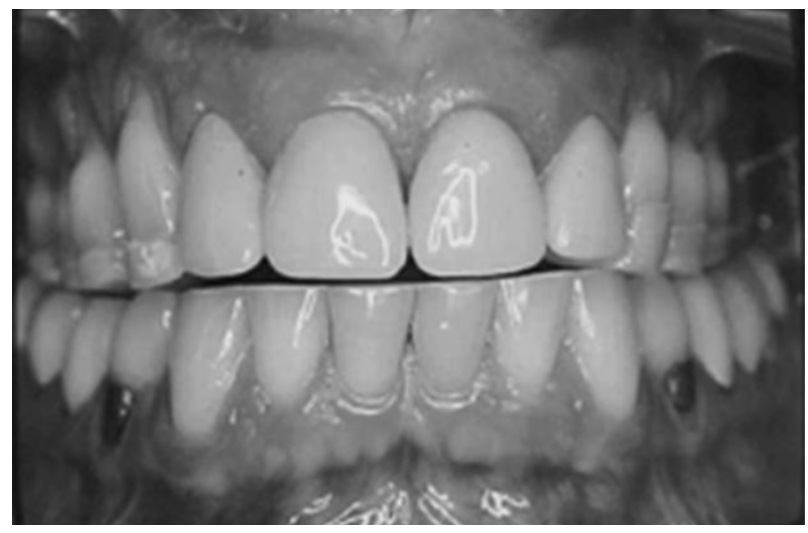

Figure 7 The anterior teeth received provisional acrylic crowns, while the posterior teeth remained with the acrylic overlay to increase vertical dimension. Posterior teeth were further prepared for fixed ceramic crowns one by one, in the same way as the anterior teeth.

guides made over a waxed-up model. Some advantages of using direct procedures with resin composite include shortening procedure time, having immediate results, and providing good esthetics at a low cost. The advent of adhesion has changed the philosophy and treatment approach of restorative dentistry. Adhesive restorations have become the first choice among direct restorative techniques and have got important space also in indirect techniques, when associated with resin luting cements. After the enamel etching proposed by Buonocore, ${ }^{35}$ dental substrate started to participate in the retention process of the restorations. Moreover, the development of bifunctional primers started to use the dentin as an available substrate as well, since the hybrid layer report by Nakabayashi et al. ${ }^{36}$ The evolution of dentin-bonding agents in the last decades provided adhesive systems with adequate bond strength, good marginal sealing, and satisfactory clinical performance. Basically, two types of adhesive systems

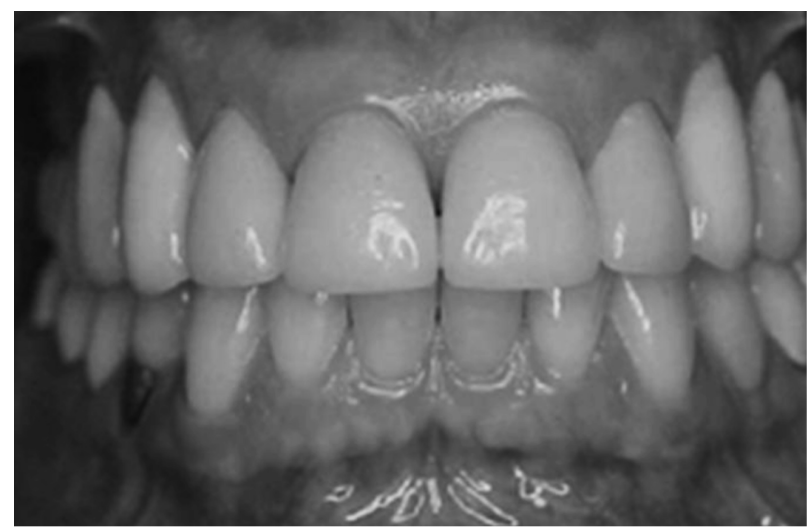

Figure 8 The provisional overlay was completely substituted by anterior and posterior ceramic fixed prosthesis. The vertical dimension was reestablished and the satisfactory esthetic and function were provided. 
are available: etch-and-rinse, which could be offered in three or two steps; or self-etching, which is divided in two steps or all-in-one. ${ }^{37}$ Indeed, both three-step etch-and-rinse and twostep self-etching adhesive systems have optimum mechanical behavior. However, the long-term degradation still seems to be the major problem related to the adhesion, and it is more relevant when associated with one-bottle adhesive systems. ${ }^{38}$ Nevertheless, there is a lack of scientific information about the performance of the adhesive systems in bruxism-related patients.

Regarding the choice for direct and indirect restorative options for oral rehabilitation of patients, there is no consensus in the literature about the best materials and techniques. Katsoulis et $\mathrm{al}^{27}$ evaluated the rehabilitation of partially edentulous patients with severe tooth wear through fixed and removable prosthesis, and found 50\% success of these prosthetic treatments after 3-year follow-up. The same authors considered the rehabilitation of such patients as difficult procedures. Kukrer et al, ${ }^{39}$ in a prospective evaluation, performed the rehabilitation of 51 patients (with or without bruxism) with ceromer inlays and found $29 \%$ of the restorations with surface damages in only 28-month follow-up. ${ }^{39}$ Hamburger et $\mathrm{al}^{34}$ conducted a retrospective clinical evaluation of 18 patients with severe tooth wear who were rehabilitated with direct composite restorations, and found good clinical performance of restorations after 4-year follow-up. In that survey, the patients were satisfied with the restorative treatment and there was only $6.9 \%$ of restoration failures.

Beier et $\mathrm{al}^{40}$ showed a retrospective clinical evaluation of 1,335 all-ceramic restorations, being: 470 crowns, 318 veneers, 213 onlays, and 334 inlays, with a mean survival time of 102 months. The authors found 95 failures, and the survival rate was $93.5 \%$ for 10 years and $78.5 \%$ for 20 years. They established 2.3 times higher the risk of failures for bruxism-related patients. Beier et al, ${ }^{41}$ in another study, provided a retrospective clinical evaluation of ceramic laminate veneers and demonstrated $82.9 \%$ of success in 20 years, but with 7.7 times higher the risk of failures when bruxism was associated. ${ }^{41}$ Granell-Ruiz et al ${ }^{42}$ also worked with porcelain veneers in a clinical study, comparing patients with and without bruxism activity and found most of the fractures and debonding occurrences were related to the presence of bruxism. Also, they established that the use of occlusal splint device reduces the risk of fractures of the veneers.

A new kind of material, hybrid ceramics, seems to be an interesting option to rehabilitate bruxism-related patients.
These materials are a type of reinforced composite with less hardness and modulus of elasticity than a ceramic, and could be indicated for onlays and occlusal veneers (table tops) in severe tooth wear situations. Johnson et $\mathrm{al}^{43}$ showed a favorable in vitro fracture resistance for Lava Ultimate (3M ESPE) with a thickness of $0.3,0.6$, and $1.0 \mathrm{~mm}$ placed on occlusal surfaces. However, there is no scientific evidence based on clinical studies to support this technique so far.

Considering the restorative material itself, Demarco et al ${ }^{44}$ reported that the materials properties are minor related to longevity. According to Yap et al, ${ }^{45}$ there is no correlation between the superficial hardness and the clinical wear of the restorative materials. Among the different direct materials, the amalgam is associated with a minor wear rate than the composite resin; and both have minor wear rates than the glass ionomer cement. Nonetheless, an important information stated by Hamburger et al, ${ }^{34}$ in an in vitro study, is that the increasing of the thickness of ceramic and composite was capable to improve the strength, with some brand variations though.

Regarding the worn anterior teeth and their occlusion guidances, Pontons-Melo et $\mathrm{al}^{46}$ proposed a minimally invasive approach, adding composite directly to restore worn anterior teeth. However, Gulamali et $\mathrm{al}^{47}$ showed a higher number of failures in these kinds of worn teeth restorations, approximately 50\% in 7-year follow-up. On the other hand, Eliyas and Martin ${ }^{48}$ used palatal gold restorations in canines to restore the guidance.

Indeed, one of the most critical points about the oral rehabilitation of bruxism-related patients is the long-term success. Therefore, longitudinal clinical evaluation studies are very important in this context. In bruxism-related patients, the most common failures found in the restorations evaluated are associated with fractures. Demarco et $\mathrm{al}^{44}$ reported the higher risk of fractures of the restorations in bruxism-related patients. Among the different kinds of failures found in the study by Beier et al, ${ }^{40}$ fracture was the main reason for failure. The clinical study by van de Sande et $\mathrm{al}^{49}$ showed that fracture events was the main reason for failure of the composite restorations in posterior teeth, especially in bruxism-related patients. They concluded that survival of restorations is affected by patient's risk factors.

Therefore, there is no consensus in the literature about the etiology, treatment, and the consequences of long-term bruxism for the patients. However, some features could be highlighted so far, related to bruxism. The use of oral appliance (interocclusal splint device) seems to be interesting 
for controlling the bruxism and its consequences. ${ }^{42,50}$ The increasing of the vertical dimension of bruxism-related patients with severe tooth wear seems to be an important step in the rehabilitation planning. ${ }^{34}$ Among the dental materials available, modern composite resins have been an alternative option for bruxism patients, inserted in the minimally invasive approach trend. ${ }^{34,46}$ In these situations, the increasing of the thickness of the composites could be interesting for the improvement of the material's resistance. ${ }^{34}$ The longevity of restorations in patients with bruxism is dependent on having additional regular recalls for patients' maintenance, and using interocclusal appliances after rehabilitation. It is important to emphasize the lack of scientific evidence about the behavior of restorative materials and techniques in patients with bruxism, especially in long-term follow-up. The encouragement to do new clinical trials about bruxism is necessary.

\section{Implants}

The literature shows many controversies about the placement of implants in patients with bruxism. While Harder et $\mathrm{al}^{51}$ showed that implants could be used to rehabilitate bruxers in various prosthetic indications with fixed and removable prostheses with no implant fractures or loss, Komiyama et $\mathrm{al}^{52}$ reported that the occlusal overload caused by tooth grinding may be related to the risk of loss of osseointegration, implant fracture, veneering materials damage, and screw loosening of implant-supported fixed partial dentures. No scientific evidences exist to date, decisions of whether to place implants in patients with bruxism are based on clinical experience and practical guidelines only and should be carefully planned by the dental professional. ${ }^{53-55}$

\section{Conclusion}

Bruxism is considered a common parafunctional habit nowadays, either while sleeping or awake. New insights have been gained into SB and professionals should update their skills and knowledge about SB etiology, treatment, and rehabilitation. Rehabilitation approaches rely on clinical experience of experts rather than on scientific evidences due to few researches about the rehabilitation of tooth wear in patients with SB. In this context, conservative and reversible treatments are preferred to restore the vertical dimension of occlusion, which is frequently required to create space for restoration material and anterior esthetic corrections. The longevity of restorations in bruxismrelated patients is still unclear. The use of an occlusal splint device seems to be an interesting option when associated with bruxism-related patients' rehabilitation.

\section{Acknowledgment}

The authors appreciate the help of the dental student Bruna Gravina in text formatting.

\section{Disclosure}

The authors report no conflicts of interest in this work.

\section{References}

1. Lavigne GJ, Huynh N, Kato T, et al. Genesis of sleep bruxism: motor and autonomic-cardiac interactions. Arch Oral Biol. 2007;52:381-384.

2. Lobbezoo F, Ahlberg J, Glaros AG, et al. Bruxism defined and graded: an international consensus. J Oral Rehabil. 2013;40:2-4.

3. Khoury S, Rouleau GA, Rompre PH, Mayer P, Montplaisir JY, Lavigne GJ. A significant increase in breathing amplitude precedes sleep bruxism. Chest. 2008;134:332-337.

4. Lavigne GJ, Kato T, Kolta A, Sessle BJ. Neurobiological mechanisms involved in sleep bruxism. Crit Rev Oral Biol Med. 2003;14: $30-46$.

5. Lavigne GJ, Rompre PH, Poirier G, Huard H, Kato T, Montplaisir JY. Rhythmic masticatory muscle activity during sleep in humans. J Dent Res. 2001;80:443-448.

6. Kato T, Rompre P, Montplaisir JY, Sessle BJ, Lavigne GJ. Sleep bruxism: an oromotor activity secondary to micro-arousal. J Dent Res. 2001;80:1940-1944.

7. Schames SE, Schames J, Schames M, Chagall-Gungur SS. Sleep bruxism, an autonomic self-regulating response by triggering the trigeminal cardiac reflex. J Calif Dent Assoc. 2012;40:670-671.

8. Lavigne GJ, Khoury S, Abe S, Yamaguchi T, Raphael K. Bruxism physiology and pathology: an overview for clinicians. J Oral Rehabil. 2008:35:476-494

9. American Academy of Sleep Medicine. International Classification of Sleep Disorders, Revised: Diagnostic and Coding Manual.2nd. ed. Westchester, IL: American Academy of Sleep Medicine; 2005: 182-185.

10. Lobbezoo F, Naeije M. Bruxism is mainly regulated centrally, not peripherally. J Oral Rehabil. 2001;28:1085-1091

11. Sato C, Sato S, Takashina H, Ishii H, Onozuka M, Sasaguri K. Bruxism affects stress responses in stressed rats. Clin Oral Investig. 2009;14: 153-160.

12. Winocur E, Uziel N, Lisha T, Goldsmith C, Eli I. Self-reported bruxism associations with perceived stress, motivation for control, dental anxiety and gagging. J Oral Rehabil. 2011;38:3-11.

13. Ohmure H, Oikawa K, Kanematsu K, et al. Influence of experimental esophageal acidification on sleep bruxism: a randomized trial. $J$ Dent Res. 2011;90:665-671.

14. Miyawaki S, Tanimoto Y, Araki Y, Katayama A, Fujii A, Takano-Yamamoto T. Association between nocturnal bruxism and gastroesophageal reflux. Sleep. 2003;26:888-892.

15. Miyawaki S, Tanimoto Y, Araki Y, Katayama A, Imai M, Takano-Yamamoto T. Relationships among nocturnal jaw muscle activities, decreased esophageal $\mathrm{pH}$, and sleep positions. Am J Orthod Dentofacial Orthop. 2004;126:615-619.

16. Giraki M, Schneider C, Schafer R, et al. Correlation between stress, stress-coping and current sleep bruxism. Head Face Med. 2010;6:2.

17. Mengatto CM, Dalberto Cda S, Scheeren B, Barros SG. Association between sleep bruxism and gastroesophageal reflux disease. J Prosthet Dent. 2013;110:349-355.

18. Carotenuto M, Parisi P, Esposito M, Cortese S, Elia M. Sleep alterations in children with refractory epileptic encephalopathies: a polysomnographic study. Epilepsy Behav. 2014;35:50-53.

19. Bellini B, Arruda M, Cescut A, et al. Headache and comorbidity in children and adolescents. J Headache Pain. 2013;14:79.

20. Esposito M, Parisi P, Miano S, Carotenuto M. Migraine and periodic limb movement disorders in sleep in children: a preliminary case-control study. J Headache Pain. 2013;14:57. 
21. Carotenuto M, Guidetti V, Ruju F, Galli F, Tagliente FR, Pascotto A. Headache disorders as risk factors for sleep disturbances in school aged children. J Headache Pain. 2005;6:268-270.

22. Lobbezoo F, Naeije M. A reliability study of clinical tooth wear measurements. J Prosthet Dent. 2001;86:597-602.

23. Machado NA, Fonseca RB, Branco CA, Barbosa GA, Fernandes Neto AJ, Soares CJ. Dental wear caused by association between bruxism and gastroesophageal reflux disease: a rehabilitation report. J Appl Oral Sci. 2007;15:327-333.

24. Alfadda SA. A conservative and reversible approach for restoring worn teeth: a clinical report. J Prosthet Dent. 2014;112:18-21.

25. Mehta SB, Banerji S, Millar BJ, Suarez-Feito JM. Current concepts on the management of tooth wear: part 1. Assessment, treatment planning and strategies for the prevention and the passive management of tooth wear. Br Dent J. 2012;212:17-27.

26. Papagianni CE, van der Meulen MJ, Naeije M, Lobbezoo F. Oral health-related quality of life in patients with tooth wear. J Oral Rehabil. 2013;40:185-190.

27. Katsoulis J, Nikitovic SG, Spreng S, Neuhaus K, Mericske-Stern R. Prosthetic rehabilitation and treatment outcome of partially edentulous patients with severe tooth wear: 3-years results. J Dent. 2011;39: 662-671.

28. Johansson A, Omar R, Carlsson GE. Bruxism and prosthetic treatment: a critical review. J Prosthodont Res. 2011;55:127-136.

29. Turner KA, Missirlian DM. Restoration of the extremely worn dentition. J Prosthet Dent. 1984;52:467-474.

30. Moshaverinia A, Kar K, Aalam AA, Takanashi K, Kim JW, Chee WW. A multidisciplinary approach for the rehabilitation of a patient with an excessively worn dentition: a clinical report. J Prosthet Dent. 2014;111 259-263.

31. Fonseca J, Nicolau P, Daher T. Maxillary overlay removable partial dentures for the restoration of worn teeth. Compend Contin Educ Dent. 2011;32(3):14-20.

32. Carlsson GE, Ingervall B, Kocak G. Effect of increasing vertical dimension on the masticatory system in subjects with natural teeth. J Prosthet Dent. 1979;41:284-289.

33. Dietschi D, Argente A. A comprehensive and conservative approach for the restoration of abrasion and erosion. Part I: concepts and clinical rationale for early intervention using adhesive techniques. Eur J Esthet Dent. 2011;6:20-33.

34. Hamburger JT, Opdam NJ, Bronkhorst EM, Kreulen CM, Roeters JJ, Huysmans MC. Clinical performance of direct composite restorations for treatment of severe tooth wear. J Adhes Dent. 2011;13:585-593.

35. Buonocore MG. A simple method of increasing the adhesion of acrylic filling materials to enamel surfaces. J Dent Res. 1955;34:849-853.

36. Nakabayashi N, Kojima K, Masuhara E. The promotion of adhesion by the infiltration of monomers into tooth substrates. J Biomed Mater Res. 1982;16:265-273.

37. Van Meerbeek B, De Munck J, Mattar D, Van Landuyt K, Lambrechts P. Microtensile bond strengths of an etch\&rinse and self-etch adhesive to enamel and dentin as a function of surface treatment. Oper Dent. 2003;28:647-660.
38. Ozer F, Blatz MB. Self-etch and etch-and-rinse adhesive systems in clinical dentistry. Compend Contin Educ Dent. 2013;34:12-14.

39. Kukrer D, Gemalmaz D, Kuybulu EO, Bozkurt FO. A prospective clinical study of ceromer inlays: results up to 53 months. Int J Prosthodont. 2004; 17:17-23.

40. Beier US, Kapferer I, Dumfahrt H. Clinical long-term evaluation and failure characteristics of 1,335 all-ceramic restorations. Int $J$ Prosthodont. 2012;25:70-78.

41. Beier US, Kapferer I, Burtscher D, Dumfahrt H. Clinical performance of porcelain laminate veneers for up to 20 years. Int J Prosthodont. 2012;25:79-85.

42. Granell-Ruiz M,Agustin-Panadero R, Fons-FontA, Roman-Rodriguez JL, Sola-Ruiz MF. Influence of bruxism on survival of porcelain laminate veneers. Med Oral Patol Oral Cir Bucal. 2014;19:e426-e432.

43. Johnson AC, Versluis A, Tantbirojn D, Ahuja S. Fracture strength of CAD/CAM composite and composite-ceramic occlusal veneers. J Prosthodont Res. 2014;58:107-114.

44. Demarco FF, Correa MB, Cenci MS, Moraes RR, Opdam NJ. Longevity of posterior composite restorations: not only a matter of materials. Dent Mater. 2012;28:87-101.

45. Yap AU, Teoh SH, Hastings GW, Lu CS. Comparative wear ranking of dental restorative materials utilizing different wear simulation modes. J Oral Rehabil. 1997;24:574-580.

46. Pontons-Melo JC, Pizzatto E, Furuse AY, Mondelli J. A conservative approach for restoring anterior guidance: a case report. J Esthet Restor Dent. 2012;24:171-182.

47. Gulamali AB, Hemmings KW, Tredwin CJ, Petrie A. Survival analysis of composite Dahl restorations provided to manage localised anterior tooth wear (ten year follow-up). Br Dent J. 2011;211:E9.

48. Eliyas S, Martin N. The management of anterior tooth wear using gold palatal veneers in canine guidance. Br Dent J. 2013;214:291-297.

49. van de Sande MA, van Geldorp NH, Dijkstra PD, Taminiau AH. Surgical technique: Tibia cortical strut autograft interposition arthrodesis after distal radius resection. Clin Orthop Relat Res. 2013;471:803-813.

50. Manfredini D, Ahlberg J, Winocur E, Lobbezoo F. Management of sleep bruxism in adults: a qualitative systematic literature review. J Oral Rehabil. 2015;42:862-874.

51. Harder S, Wolfart S, Egert C, Kern M. Three-year clinical outcome of single implant-retained mandibular overdentures - results of preliminary prospective study. J Dent. 2011;39:656-661.

52. Komiyama O, Lobbezoo F, De Laat A, et al. Clinical management of implant prostheses in patients with bruxism. Int J Biomater. 2012;2012:369063.

53. Lobbezoo F, Brouwers JE, Cune MS, Naeije M. Dental implants in patients with bruxing habits. J Oral Rehabil. 2006;33:152-159.

54. Manfredini D, Bucci MB, Sabattini VB, Lobbezoo F. Bruxism: overview of current knowledge and suggestions for dental implants planning. Cranio. 2011;29:304-312.

55. Lobbezoo F, Van Der Zaag J, Naeije M. Bruxism: its multiple causes and its effects on dental implants - an updated review. J Oral Rehabil. 2006;33:293-300

Clinical, Cosmetic and Investigational Dentistry

\section{Publish your work in this journal}

Clinical, Cosmetic and Investigational Dentistry is an international, peer-reviewed, open access, online journal focusing on the latest clinical and experimental research in dentistry with specific emphasis on cosmetic interventions. Innovative developments in dental materials, techniques and devices that improve outcomes and patient satisfac-

tion and preference will be highlighted. The manuscript management system is completely online and includes a very quick and fair peerreview system, which is all easy to use. Visit http://www.dovepress $\mathrm{com} /$ testimonials.php to read real quotes from published authors. 